\title{
Stage I Prostate Cancer AJCC v8
}

National Cancer Institute

\section{Source}

National Cancer Institute. Stage I Prostate Cancer A/CC v8. NCI Thesaurus. Code C140164.

Stage I includes: (cT1a-c, cT2a, N0, M0, PSA less than 10, Grade Group 1); (pT 2, N0, M0, PSA less than 10, Grade Group 1). cT1a: Prostate cancer in which the tumor is an incidental histologic finding in 5\% or less of tissue resected. cT 1b: Prostate cancer in which the tumor is an incidental histologic finding in more than $5 \%$ of tissue resected. CT 1c: Prostate cancer in which the tumor is identified by needle biopsy found in one or both sides, but not palpable. сT2a: Prostate cancer in which the tumor involves one-half of one side or less. pT2: Prostate cancer which is organ confined. N0: Prostate cancer with no positive regional nodes. M0: Prostate cancer without evidence of distant metastasis. Grade Group 1: Gleason Score 6 or less, Gleason Pattern 3 or less+3. (AJCC 8th ed.) 